\title{
Promising directions in the selection of peach, apricot and nectarine
}

\author{
Anatoly Smykov", Evgeny Shoferistov, Vadim Korzin, Natalya Mesyats, and Nikita Saplev \\ FSBIS "Order of the Red Banner of Labor Nikitsky Botanical Gardens - National Scientific Center of \\ the Russian Academy of Sciences", 298648 Yalta, Russia
}

\begin{abstract}
The collection of stone fruit crops (peach, apricot and nectarine) was analyzed in accordance with their belonging to certain ecologicalgeographical groups and ecotypes. The most valuable characteristics were determined, sources of economically valuable properties were identified, and included in crossbreeding combinations for intraspecific and interspecific hybridization. Methods of radiation and chemical mutagenesis were used in the selection of peach and apricot. New genotypes with different levels of susceptibility to common diseases have been created. As a result of breeding, new varieties of stone fruit crops selected by NBG were introduced into the Register of Plant Varieties of the Russian Federation: 28 peaches, 3 nectarines, 15 apricots.
\end{abstract}

\section{Introduction}

Stone fruit crops peach, nectarine and apricot are among the most significant for the horticulture of the Crimea and southern Russia. The areas of peach and nectarine in the Republic of the Crimea in the structure of plantations occupy $25.2 \%$ or 2.6 thousand hectares. The ripening period for these crops is extended by 3-3.5 months (from the end of June to September), which meet the demand for fresh fruit products in the summer months. Apricot in the Crimea occupies about one thousand hectares (9.5\%). Its fruits begin to ripen two and a half weeks earlier than the peach and expand the conveyor for the supply of fruit products to the consumer. The rich chemical composition, good taste of the fruits increase the popularity of apricot and complement the diet of the Crimean people. But in the existing varieties of peach, nectarine and apricot there are not enough early- and late-ripening varieties with high commercial qualities, especially peach with yellow pulp. It is also necessary to obtain new varieties of these crops resistant to the most common diseases, unfavorable abiotic and biotic environmental factors.

The gene collection of stone fruit crops in the Nikitsky Botanical Gardens was formed by breeders of the laboratory of southern fruit crops by obtaining their own hybrid forms and varieties, as well as by introducing genotypes from various UIS countries, America, Europe and Asia $[1,2,3,4]$.

\footnotetext{
${ }^{*}$ Corresponding author: selectfruit@yandex.ru
} 
The aim of the research was to summarize the material of many years researches on the study of the gene collection and selection of peach, apricot and nectarine for the Crimea and the south of the Russian Federation.

\section{Materials and methods}

The peach gene collection in the NBG has 790 varieties and forms. There are 706 varieties and forms of apricot. The nectarine collection consists of 85 specimens. Gene pool studies were carried out according to the generally accepted methods of the NBS [5, 6, 7]. Varieties and forms were divided into ecological-geographical groups and ecotypes. A complex study of the samples was carried out, the cultivars with economically valuable characteristics resistant to diseases, to biotic and abiotic factors were selected.

The statistical evaluation of the experimental data was carried out according to the method of B.A. Dospekhov [8] based on software "Microsoft Exel 2007" and "Statistica $10 "$.

\section{Results and discussion}

The breeding process in the NBG takes place according to the established plan in several stages. The basis for the obtaining of new genotypes is intraspecific and distant crosses. They are classified into direct, indirect, repeated, and inbreeding. In some combinations of crossing, peach pollen was pretreated with gamma radiation. When crossing early maturing varieties, the seeds were handed to the biotechnology laboratory for growing in vitro culture.

The obtained hybrid seedlings were placed in a selection garden and studied for economically valuable characteristics during the first fruiting period. The selected forms were transferred to the stock in an amount of at least five plants and studied according to the method of primary study in the collection. The forms on the rootstock were studied more detailed than the seedlings. A complex study of phenological, biochemical, physiological, pomological indicators of new genotypes was carried out. Those forms that surpass the existing varieties in a number of characteristics were handed for state variety testing and included in the Register of Plant Breeding Achievements of the Russian Federation.

The varieties and forms in the collection of peach were divided, in accordance with phenotypic characters, into ecological-geographical groups and ecotypes (Fig. 1). The maximum number of genotypes (47\%) belongs to the Iranian group of the European ecotype.
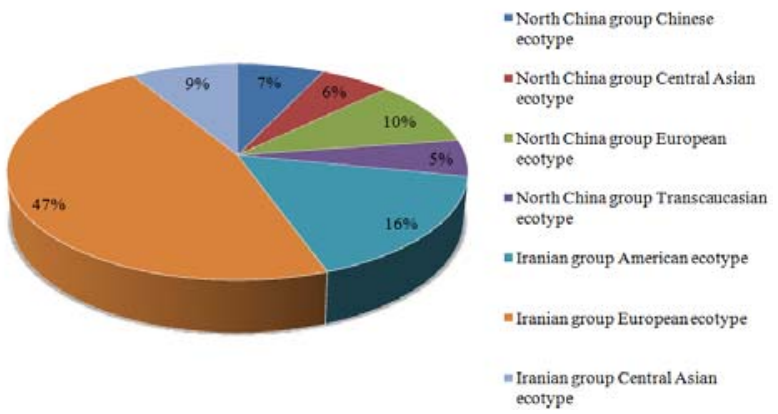

Fig. 1.Distribution of varieties and forms of peach in the collection 
Peach samples were divided according to their valuable characteristics: 62 varieties with fruits of early ripening period, 6 - late ripening, 60 - early-ripening, 14 - with high yields, 111 - with high commercial qualities, 17 - with late flowering, 16 - with a high degree of flowering, 22 - with a long flowering period, 14 - with increased adaptability to frost, 32 drought tolerance, 4 - weak resistance to leaf curl, 10 - weak resistance to mildew.

To obtain genotypes resistant to fungal diseases, crosses were carried out with tolerant varieties Stoyka, Tovarishch, Fergansky Yellow and Orfey, which are sources of increased resistance to these diseases. To obtain seedlings with high commercial qualities, varieties Zolotaya Moskva, FavoritaMorettini, Springold, Redhaven, Collins, Golden Jubilee, Spartak, Michelini, Kremlevsky, Baby Gold-5, Armgold, etc. were used in hybridization.

A number of saturating (return) crosses were carried out: (Vostok 3 x Tovarishch 83845) x Tovarishch, (Veteran x Tovarishch 84-2589) x Tovarishch, (Zlatogor x Ak Sheftal Kesma 84-3) x Ak Sheftal Kesma, (Kosmichesky x Ak Sheftal Kesma 84-10) x Ak Sheftal Kesma; reciprocal: Veteran x Ak Sheftal Kesma, Ak Sheftal Kesma x Veteran, Veteran x Tovarishch, Tovarishch x Veteran, Golden JubileehTovarishch, Tovarishch x Golden Jubilee, Spartak x Kremlyevsky, Kremlyevsky x Spartak.

The process of interspecific hybridization with nectarine involves Fergana peach (Prunus ferganensis (Kostov \& Rjabov) Kovalev \& Kostov) represented by the following varieties: Sovkhozny, Fergansky Zhyelty, Fergansky Bely, Fergana-type nectarine variety Lyuchak, as well as nectarine variety Mirabelny of the Iranian group, nectarine varieties of the North Chinese group: Uvesisty, Flavortop, Kzyl Shalili, honey peach of the northern Chinese group Tszyu-Yus-Ju, wild species of Prunus davidiana (Carr.) Franch., P. kansuensis Rehd., P. mira Koehne and their interspecific hybrids with nectarine. Ten combinations of crossing were carried out, 13,490 flowers were castrated and pollinated, $8.7 \%$ of ovaries were formed, and 1177 hybrid fruits were obtained (long-term data) [9].

Fergana-type nectarines with fertile pollen have been obtained (Nectarenzis 358-84, Nectarenzis 592-81, Nectarenzis 594-81), with male sterility, with increased resistance to mildew, with sweet fruit taste, with cartilaginous pulp consistency and flat fruits Fergansky Plosky 267-72 (Fergansky Bely self-op.) [10].

Nikitsky Botanical Gardens (NBG) in its collections has nectarine genotypes with male sterility (Kulzhinsky 2x, Kuldzhinsky 4x, Baikola, Nectared 10, Nectakuldzh 142-91, Sergo 152-91, etc.). They are an important breeding material for the obtaining of rootstocks, rootstock-seed mother plantations, and for obtaining interspecific hybrids between Prunus persica and Prunus amygdalus [11].

According to the studying results of the nectarine field resistance to fungal diseases, varieties and forms with different degrees of resistance to mildew and curly leaves were noted (Fig. 2). The breeding form 512-86 was identified as the most resistant to mildew over the years of research. Genotypes 485-86, 488-86, 491-86, 492-86, 500-86, 512-86 are also noted to be weakly susceptible to powdery mildew [10]. All the studied cultivars were moderately affected by the curliness of the leaves, and in the years of epiphytoties, the maximum number of leaf damage was noted ( 9 points). 


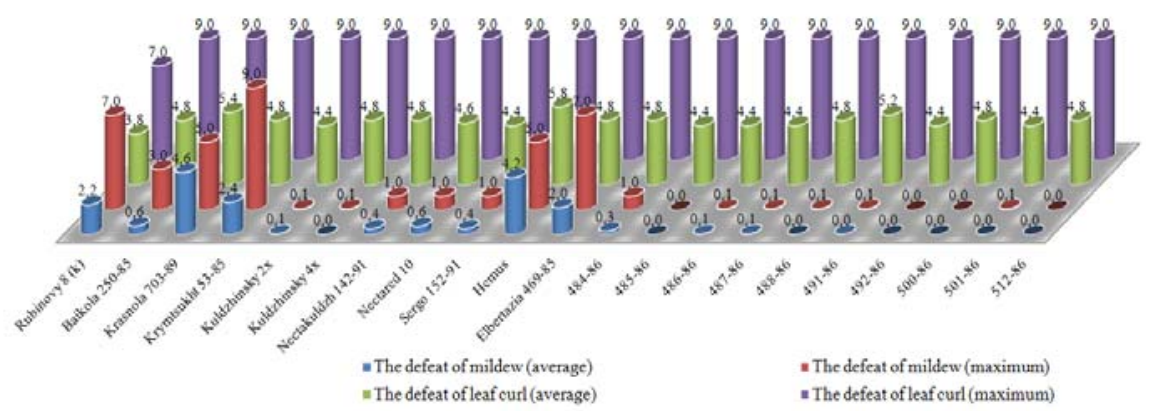

Fig. 2.Degree of fungal diseases affecting varieties and forms of nectarine (on a 9-point scale), longterm data.

For state variety testing were handed 10 nectarine varieties of NBG selection: Rubinovy 4, Rubinovy 7, Suvenir Nikitsky, Ametist, Ishunsky, Evpatorisky, Nikitsky 85, Krymtsukht, Neugasimy, Poseidon; 3 varieties were included in the Register of Plant Breeding Achievements of the Russian Federation (Krymchanin, Rubinovy 8, Rubinovy 9).

One of the reasons limiting the distribution of apricots in the world is the short period of winter dormancy and the rapid development of generative buds in early spring. This leads to the fact that flower buds die even with small recurrent spring frosts $[12,13]$.

The following differences are observed in terms of flowering periods in ecologicalgeographical groups (Fig. 3).

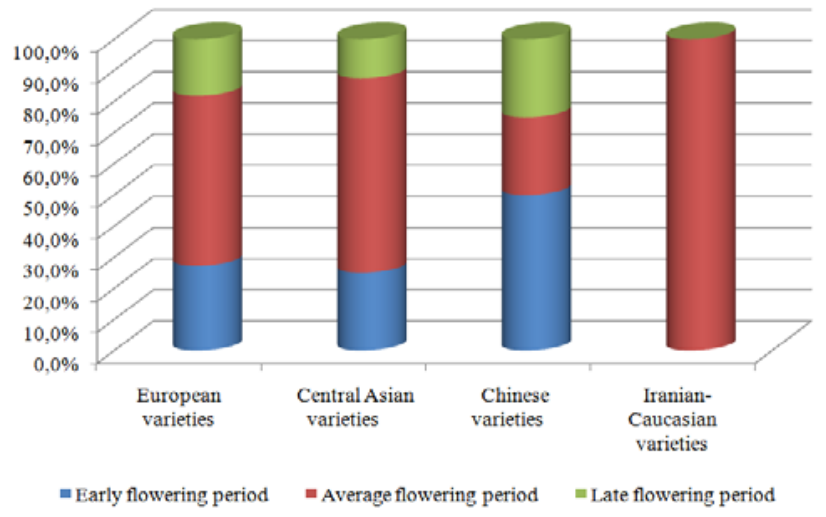

Fig. 3. Distribution of varieties and forms of apricot by flowering periods.

Of all the genotypes included in the study, 57 varieties and forms with late flowering were selected. 22 varieties and 23 forms among them are of NBG selection: Aspirant, Vecherny Krym, Zapozdaly, Rusich, Apogey Nikitsky, Aniskin, Nairi, 8103, 89-363, 10794, etc.; 12 are introduced species: 22-3, Patterson, Dessertny Venyaminova, Lemon Belokalitvensky Pozdny, Chyerny Barkhat, Sophinka, etc. These genotypes bloom 1-2 weeks later than all other apricot plants and can be used as sources of these characteristics in breeding.

The researches of breeders all over the world are devoted to the extension of the period of fruit ripening due to the obtaining and introduction of earlier and later varieties, in relation to the existing ones. In the Iranian-Caucasian group, varieties with medium ripening periods prevail (up to $90 \%$ ), $10 \%$ of genotypes selected among the late ones. In the Central Asian group, varieties with early (Kok Pshar), medium (Ruhi Zuvanon Surkh, Lyuchak Sumbarskiy) and late (Kech Pshar) fruit ripening periods are selected. In the Chinese group, $43 \%$ of early-ripening and medium-ripening varieties, and $14 \%$ of late- 
ripening varieties were selected. In the hybrid group, 14 varieties and 10 forms of NBG selection with early fruit ripening were identified: Edem, Priusadebny Ranniy, Rannee Utro, Apricot from 8 sq., Olis, Novator, Frunzensky Ananasovy, 8534, Zorky irradiated 9/14, Zorky irradiated 10/1, Zorky irradiated 9/9, Cytology 115, 97-10, etc. Two early genotypes with the fruits which ripen in early June bred in NBG Edem and 8534 were selected. 38 genotypes with late maturation (late July - early August) were identified. Among them there are eight varieties of NBG breeding (Vynoslivy, Chudo, Yakhont Kryma, Sakharny, Barz, Perekopsky, Brigmas 2, Ananasny Avgustovsky) and 14 breeding forms (Selection15/36, Poznetsvetushchy No. 16, 8099, 9636, 89-164, etc.), 16 introduced ones (Pol Robson, Da-Huang-Hou, Sirena, Chyerny Barkhat, Weslay-25, Lerana, Sophinka, Aresh Sanagyan, 15-5-53, etc.). Three genotypes of NBG breeding, having the latest fruit ripening periods Arzami Karminovy, Poznetsvetushchy No. 16, 8103 and three introduced ones Aresh Sanagyan (Iranian-Caucasian group), Lemon Belokalitvensky Pozdny and 15-553 (European group) were selected.The selected early- and late-ripening varieties and forms are of interest for increasing the period of fresh fruit supply to the population. The selected genotypes are recommended to be used as a possible source of this characteristics.

Apricot varieties of European selection (20\%) and from the hybrid group (34\%) were selected according to the productivity. These are such varieties as: Zvezdochyet, Shedevr, Mister, Kostinsky, Yarilo, Kioto, Mandule Kajzsi, Lerana, 15-5-53, 8531, 8708, etc. The selected genotypes are recommended to be used as a possible source of this characteristic.

To obtain annual, stable yields, an important role for fruit crops play the ability to pollinate with their own pollen. This is especially true for apricots, nectarines and peaches, as their flowering very often takes place under unfavorable climatic conditions. A more detailed examination of the ability of peach varieties to set fruit revealed that the largest number of self-fertile cultivars is found in the American ecotype (31 varieties). When analyzing the apricot gene fund for this characteristic, significant differences were revealed in ecological-geographical groups: most (over 70\%) varieties of the hybrid group are selffertile, in Central Asian varieties they do not exceed 5\%, in European varieties $-21 \%$.

In the Crimea, water deficit is usually observed in August. As a result of the studies, it was revealed that varieties from the Central Asian region have the highest drought resistance. Among all studied varieties, the following ones are distinguished by increased drought resistance: VardaguinVagdaas (Iranian-Caucasian variety), Lyuchak Sumbarsky (Central Asian variety) and LE-132 form (European group). Variety Boyarin and form Pamyat o Druge are distinguished by high drought resistance. The selected genotypes are promising sources of this characteristic for breeding.

One of the most harmful diseases for apricots is moniliosis (Monilia cinerea Bon.) [14]. It causes browning, and then drying out of flowers and shoots. During fruiting - fruit wrath. Seven genotypes were selected (plant damage did not exceed 2 points): Nukul Citronny (Central Asia), Samarkandsky Ranny(Central Asia), Krasnoshchyeky (Europe), 1989 (Hungary), Budapest (Hungary), 7(3)-3-70 b (Moldova), Stokk (USA). 60\% of varieties and forms resistant to this disease have been selected from the breeding gene collections of the Nikitsky Botanical Gardens. These are such varieties as: Autok, Iskorka Tavridy, Aviator, Professor Smykov, Vognik, Magister, Vynoslivy, Zevs, etc. The spread of apricot in the Crimea and southern Russia also limits the damage of plants by clasterosporium. The causative agent is fungus Clasterosporium carpophilum (Lev.) Aderh. According to the resistance to this disease, 28 genotypes were selected (plant damage did not exceed 2 points): Gevandi Krupny (Armenia), Large Early (France), Yin-Bei-Xin, Da-Huang-Hou, Mai Huang, Mai-He-Sin, (China), Mamuri, Kech Pshar, Ruhi Zuvanon Surkh, Lyuchak Sumbarsky, (Central Asia), Kiena Dryanovska (Bulgaria), Nagycorosi Orias (Hungary), Keckemeti Rozsa (Hungary), New Castle, Jumbocot (USA), Neptun (Romania ) and others, seven forms: LE-132 (Czech Republic), MK-132, 47-L/11, H-II- 25/32, H-I-36/25 
(Hungary), 89-538, 319-757, (Russia). The selected genotypes are promising sources of this characteristic for breeding. In terms of resistance to moniliosis and klyasternosporiosis, four varieties are selected: Vognik, Budapest, Nukul Citronny, Yubileiny.

In the in vitro embryo culture from varieties Salyut, Nikitsky and Dionis, apricot genotypes 55, 62, 80, 130 were bred. Form 80 differs by the average period of flowering, all the rest bloom in the early-middle period. Forms 130 and 62 are distinguished by high resistance to drought (up to 3.8 points on a 5-point scale). Form 130 is of interest for its productivity. Form 62 stands out among them by earlier fruits ripening (13.06); fruits ripen in forms 55 and 130 three to five days later. Plant forms 80 and 55 are affected by moniliosis weaker than others (by 2.1-2.8 points, respectively). Form 80 is distinguished by field resistance to moniliosis and clasterosporiosis. A number of varieties were obtained by mutagenesis from variety Zorkiy. The obtained genotypes were characterized by weak growth and bright color of the fruit, while maintaining the morphological characteristics of the original plant. It was determined that the efficiency of mutagenesis in apricot significantly depends on the selection of the starting material.

From the total number of peach seedlings obtained in the result of crossing varieties from different ecological-geographical groups and ecotypes, 47 forms were distinguished with high quality fruits, 32 with an annual productivity, 36 with a high resistance to leaf curl, and 38 - to mildew.

As a result of gamma irradiation of pollen of 23 peach varieties, the radiosensitivity and fertility of the male gametophyte of the studied samples were determined. Moderate doses and character of variability of peach characteristics were revealed after complex exposure on seeds with gamma radiation and growth stimulants: indole butyric acid and fumar, as well as on vegetative buds with chemical mutagens: ethyleneimine, nitrosoethyl urea, nitrosomethyl urea together with gamma radiation and these substances.

As a result of experimental mutagenesis, 49 forms were selected for a complex of biologically valuable characteristics, including 13 samples for frost resistance, 11 for drought resistance and 8 forms with an increased content of biologically active substances in fruits. Chromosomal aberrations were detected by the method of differential chromosome staining in radiomutant forms of peach.

\section{Conclusions}

The distribution of peach varieties and forms in the Nikitsky Botanical Gardens in two ecological-geographical groups and eight ecotypes and the use of methods of distant hybridization, experimental mutagenesis and embryoculture helped to increase the efficiency of breeding and made it possible to select 84 donors with valuable characteristics, 235 promising seedlings and 113 elite forms.

Nectarine breeding in the Nikitsky Botanical Gardens was carried out using the genetic material of wild species (Prunus ferganensis (Kostov\&Rjabov) Kovalev\& Kostov, $P$. davidiana (Carr.) Franch., P. kansuensis Rehd., P. mira Koehne) to obtain hybrids and varieties with increased resistance to fungal diseases. New genotypes with different levels of resistance to common diseases, with fertile and sterile pollen have been obtained; the peach form of the Fergana type with a honey taste of fruits, a gristly texture of the pulp and flat fruits has been selected (Fergansky Plosky 267-72).

A comprehensive study of the apricot collection using intraspecific and interspecific hybridization, mutagenesis, and in vitro culture made it possible to select 17 donors and 55 sources with valuable characteristics for further breeding (on frost resistance, drought resistance, early fruits ripening, fruit taste, late flowering, etc.). 
As a result of selection, 28 peach varieties, 16 apricot varieties, 3 nectarine varieties were bred. They are included in the Register of Varieties approved for use in the Russian Federation. 27 peach, 13 apricot and one nectarine varieties are patented.

\section{References}

1. A.V. Smykov, Collection of scientific works of the State Nikitsky Botanical Garden,140, 19 (2015)

2. Yu.V. Plugatar, A.V. Smykov, N.E. Opanasenko, A.I. Sotnik, To the creation of industrial orchards of fruit crops in the Crimea, 212 (2017)

3. V.M. Gorin, V.V. Korzin, N.V. Mesyats, N.Yu. Marchuk, Proceedings of the Kuban State Agrarian University,4(73), 32 (2018)

4. A.V. Smykov, Bulletin of the Nikitsky Botanical Garden,100, 56 (2010)

5. E.N. Sedov, T.P. Ogoltsova, Program and methodology for the study of varieties of fruit, berry and nut crops, 608 (1999)

6. U.I. Kantsaeva, V.M. Gorina, Collection of scientific works of the State Nikitsky Botanical Garden,140, 87 (2015)

7. E.N. Sedov, Program and methodology for selection of fruit, berry and nut crops, 502 (1995)

8. B.A. Dospekhov, Methodology of field experience, 351 (1985)

9. E.P. Shoferistov, Breeding of nectarine (Prunus persica (L.) Batsch subsp. nectarina (Ait.) Shof.) in Nikitsky Botanical Garden, 124 (2015)

10. E.P. Shoferistov, The role of cultivar in modern horticulture, 312 (2019)

11. Horticulture: Theory, Innovation,3(152), 71 (2019)

12. V. Korzin, V. Gorina, Acta Horticulturae,1139, 363 (2016)

13. N.V. Mesyats, V.M. Gorina, Fruit and berry growing, 54, 177 (2018)

14. V. Korzin, V. Gorina, Acta Horticulturae,1208, 151(2018) 